\title{
Suplementação mineral para bovinos de corte - uma revisão sistemática
}

\author{
Mineral supplementation for beef cattle - a meta-analysis \\ Suplementación mineral para ganado vacuno - una revisión sistemática
}

Recebido: 06/02/2022 | Revisado: 16/02/2022 | Aceito: 19/02/2022 | Publicado: 01/03/2022

Aloisio Giacomel
ORCID: https://orcid.org/0000-0002-0759-9250
Instituto Federal de Educação, Ciência e Tecnologia do Rio Grande do Sul, Brasil
E-mail: aloisiogiacomel@gmail.com
Thaís Campos de Freitas
ORCID: https://orcid.org/0000-0003-3942-599X
E-mail: thaiscamposdefreitas@gmail.com
Ana Lúcia Barreto da Costa
Instituto Federal de Educação, Ciência e Tecnologia do Rio Grande do Sul, Brasil
ORCID: https://orcid.org/0000-0002-0807-2581
E-mail: ad.costa1998@gmail.com
Edriane Mara Sbardelotto
Instituto Federal de Educação, Ciência e Tecnologia do Rio Grande do Sul, Brasil
ORCID: https://orcid.org/0000-0003-2985-5996
Instituto Federal de Educação, Ciência e Tecnologia do Rio Grande do Sul, Brasil
E-mail: edrianesbardelotto@gmail.com
Emely Bergmann
ORCID: https://orcid.org/0000-0002-8839-9209
Instituto Federal de Educação, Ciência e Tecnologia do Rio Grande do Sul, Brasil
E-mail: emelybergmann99@gmail.com
Elísio de Camargo Debortoli
Instituto Federal de Educação, Ciência e Tecnologia do Rio Grande do Sul, Brasil
E-mail: elisio.debortoli@ sertao.ifrs.edu.br

\section{Resumo}

A bovinocultura de corte no Brasil se sustenta predominantemente no uso de pastagens. No entanto, é preciso reconher as flutuações estacionais referentes a composição e concentração de nutrientes disponíveis nestas pastagens ao longo do ano nos diferentes biomas do país. Nesse sentido, espera-se também flutuações na disponibilidade de minerais através da alimentação para os bovinos, o que podem gerar deficiências, demandando suplementação. Este estudo teve como objetivo aprofundar os conhecimentos sobre a suplementação mineral de bovinos de corte, em diferentes sistemas de produção, através da investigação de trabalhos já publicados sobre o tema, nos últimos vinte anos e disponíveis em bancos de dados científicos nacionais. Foi possível evidenciar que a suplementação mineral envolve várias etapas do planejamento para a produção dos bovinos de corte, devendo o produtor possuir uma visão ampla do sistema. Essa visão abrange desde a análise do solo, a implantação e manejo de pastagens, as exigências de diferentes categorias animais e em diferentes épocas do ano, até os ajustes na formulação dos suplementos que serão fornecidos aos animais pois, se mal formulados, podem causar perdas irreparáveis nos bovinos. Sendo assim, concluise que o uso correto de suplementos minerais, trará receitas atravéz da produtividade superior e compensatória aos investimentos com a compra dos suplementos.

Palavras-chave: Eficiência produtiva; Macrominerais; Microminerais; Nutrição animal.

\begin{abstract}
Beef cattle farming in Brazil is based predominantly on pastures. However, it is necessary to recognize the seasonal fluctuations regarding the composition and concentration of nutrients available in these pastures throughout the year in the different biomes of the Brazil. In this sense, it is also expected fluctuations in the availability of minerals through feed for cattle, which can generate deficiencies, requiring supplementation. This study aimed to deepen the knowledge on mineral supplementation of beef cattle, in different production systems, through the investigation of works already published on the subject, in the last twenty years and available in national scientific databases. It was possible to show that mineral supplementation involves several stages of planning for the production of beef cattle, and the producer must have a wide view of the system. This vision ranges from soil analysis, pasture implantation and management, the requirements of different animal categories and at different seasons of the year, to adjustments in the formulation of supplements that were available to animals because, if poorly formulated, they can cause losses irreparable in cattle. Thus, conclude that the correct use of mineral supplements will bring income through superior productivity and compensatory investments with the purchase of supplements.
\end{abstract}


Keywords: Animal nutrition; Macrominerals; Microminerals; Productive efficiency.

\section{Resumen}

El ganado vacuno en Brasil se basa predominantemente en el uso de pastos. Sin embargo, es necesario reconocer las fluctuaciones estacionales en cuanto a la composición y concentración de nutrientes disponibles en estos pastos a lo largo del año en los diferentes biomas del país. En este sentido, también se esperan fluctuaciones en la disponibilidad de minerales a través de la alimentación del ganado, lo que puede generar deficiencias, requiriendo suplementación. Este estudio tuvo como objetivo profundizar el conocimiento sobre la suplementación mineral de bovinos de carne, en diferentes sistemas de producción, a través de la investigación de trabajos ya publicados sobre el tema, en los últimos veinte años y disponibles en bases de datos científicas nacionales. Se pudo evidenciar que la suplementación mineral involucra varias etapas de planificación para la producción de ganado vacuno de carne, y el productor debe tener una visión amplia del sistema. Esta visión va desde el análisis del suelo, la implementación y manejo de los pastos, los requerimientos de las diferentes categorías de animales y en las diferentes épocas del año, hasta los ajustes en la formulación de los suplementos que se les brindará a los animales porque, de estar mal formulados, pueden causar pérdidas irreparables en el ganado. Por lo tanto, se concluye que el uso correcto de los suplementos minerales traerá ingresos a través de una productividad superior y compensatoria de las inversiones con la compra de suplementos.

Palabras clave: Eficiencia productive; Macrominerales; Microminerales; Nutrición animal.

\section{Introdução}

A bovinocultura de corte se sustenta predominantemente no uso de pastagens. A qualidade destas pastagens irá resultar no desempenho produtivo desses animais. Outro fator de relevância é que estas pastagens apresentam flutuações estacionais referentes a sua composição e concentração de seus nutrientes que estarão disponíveis. Com isso, os bovinos estão suscetíveis a deficiências graves de minerais ou deficiências estacionais (Oliveira Dantas \& Mattos Negrão, 2010).

As variações na qualidade e quantidade de forragem ofertada aos bovinos no decorrer do ano refletem negativamente nos índices zootécnicos. Para melhorar esses índices torna-se necessário o uso da suplementação mineral que atenda as exigências dietéticas dos animais (Socreppa et al., 2015).

Segundo Oliveira Dantas \& Mattos Negrão (2010), nos bovinos, a idade do animal, o estado fisiológico, a categoria animal, a forma química dos elementos minerais nas dietas, o nível de produção dos animais, o consumo de sal mineral e a qualidade das pastagens, influenciam diretamente nas exigências minerais dos mesmos.

O Brasil possui o segundo maior rebanho pecuário do mundo, e em sistemas de produção representativos do país, esse rebanho é criado em pastagens nativas. Um exemplo é o estado do Rio Grande do Sul, onde a atividade pecuária ocupa 56\% do território do estado. Desses 56\%, boa parte são pastagens nativas sendo que a suplementação mineral é deficiente no decorrer do ano, ainda levando em conta o fato de que a pastagem nativa é pobre em teor proteico e em níveis minerais (Vale et al., 2003).

A propaganda realizada pelas empresas que comercializam suplementos minerais resultou em um incremento considerável na suplementação por parte dos produtores aos seus rebanhos nos últimos 30 anos. Foi uma ação positiva pois conscientizou os produtores da importância que a suplementação mineral tem para o bom desempenho dos rebanhos bovinos. Entretanto, na maior parte das vezes, as misturas minerais fornecidas são adquiridas prontas, sem levar em conta os teores de minerais das dietas (Peixoto et al., 2003),

No Brasil, sem sombra de dúvidas, existem deficiências minerais as quais causam perdas e prejuízos aos pecuaristas. Grande parte dos pecuaristas, veterinários e zootecnistas estão cientes disso, porém é necessário um olhar mais específico para determinar como suplementar esses rebanhos de uma forma mais objetiva, com um resultado mais satisfatório em termos de suplementação e também em termos econômicos (Peixoto et al., 2005).

Entre os principais elementos que geralmente fazem parte de uma mistura mineral comercial, ferro, cromo e enxofre são alguns deles, ditos elementos essenciais, ou seja, devem constar na dieta dos animais.

Porém, é muito difícil que haja deficiência desses minerais para os animais porque, na maioria das vezes, as 
exigências são supridas pela alimentação, sendo que o fornecimento destes minerais em formulações de sal mineral só estará agregando em custos e até mesmo dificultando a absorção dos minerais que realmente devem ser supridos via suplementação mineral (Peixoto et al., 2005).

A suplementação mineral pode constituir de 20 a 30\% do total dos custos de produção do gado a pasto. Com isso, ressalta-se a importância econômica que a suplementação mineral tem e que, avaliar corretamente as necessidades e exigências do rebanho, pode auxiliar na diminuição de gastos com a criação (Peixoto et al., 2005).

Ao avaliarem novilhos castrados com idade de18 meses, na região Centro-Oeste do Brasil, identificaram que os tratamentos que receberam suplementação mineral, apresentaram ganhos de peso médios superiores aos animais sem suplementação. Na análise econômica, o tratamento com suplementação mineral com melhor resultado indicou incremento de $25 \%$ na receita obtida com o aumento da produtividade dos animais em relação ao incremento de custos com a inserção da suplementação mineral (Oliveira et al., 2014).

Estudo realizado no Centro Oeste do país, para avaliar os fatores determinantes de compra de núcleos minerais na criação de bovinos de corte criados em regime de confinamento, foi notada a falta de padronização em relação aos criadores. Ou seja, a análise padronizada de dados pode ser ponto de influência positiva para melhorar as escolhas em relação aos suplementos minerais adquiridos pelos produtores (Krabbe et al., 2021).

Desta maneira, este estudo teve como objetivo aprofundar os conhecimentos sobre a suplementação mineral de bovinos de corte, em diferentes sistemas de produção, através da investigação de trabalhos já publicados sobre o tema, nos últimos vinte anos e disponíveis em bancos de dados científicos nacionais.

\section{Materiais e Métodos}

O presente estudo foi baseado primeiramente em uma revisão sistemática, que se deu pelo levantamento de dados já publicados sobre o tema suplementação mineral de bovinos de corte.

Nas últimas décadas, o grande volume das informações científicas geradas aponta para a necessidade de sínteses que facilitam o acesso às mesmas, possibilitando conclusões baseadas na combinação dos resultados oriundos de múltiplas fontes. Nas revisões sistemáticas os "sujeitos" da investigação são os estudos primários selecionados por meio de métodos sistemáticos e pré-definidos (Cordeiro et al., 2007).

De acordo com Sampaio e Mancini (2007), uma revisão sistemática disponibiliza um resumo das evidências relacionadas a determinado tema, permitindo a busca sistematizada, a apreciação crítica e a síntese das informações selecionadas.

Como critério para seleção dos trabalhos, optou-se pela busca por publicações nacionais e internacionais de estudos conduzidos no Brasil ou disponíveis em bancos de dados científicos nacionais e que foram publicados no período de 2000 a 2021. Tais trabalhos precisavam estar publicados em revistas cientificas e disponíveis de forma online. Foram utilizadas as seguintes bases de dados: Google Acadêmico, Scielo e Periódicos Capes. Inicialmente foi realizada a busca por publicações, selecionando artigos a partir da presença de palavras chave, conforme apresentado no Quadro 1.

Quadro 1. Estratégia de Busca.

Estratégia de busca: "suplementação AND mineral" AND "bovinos AND corte" OR "mineral AND supplementation" AND "beef AND cattle". 
A partir desta primeira seleção, os trabalhos foram analisados como um todo, observando dados, interpretações e resultados.

Na Figura 1 é apresentado o processo de seleção dos artigos garimpados nas bases de dados a partir da estratégia de busca. Dos 136 artigos filtrados em um primeira etapa, 66 foram selecionados para uma segunda etapa e 30 utilizados no processo de revisão. Na Tabela 1 estão listados os artigos utilizados na revisão sistemática.

Figura 1. Fluxograma da análise e seleção dos artigos para a revisão sistemática.

\section{$1^{\text {a Etapa }}$}

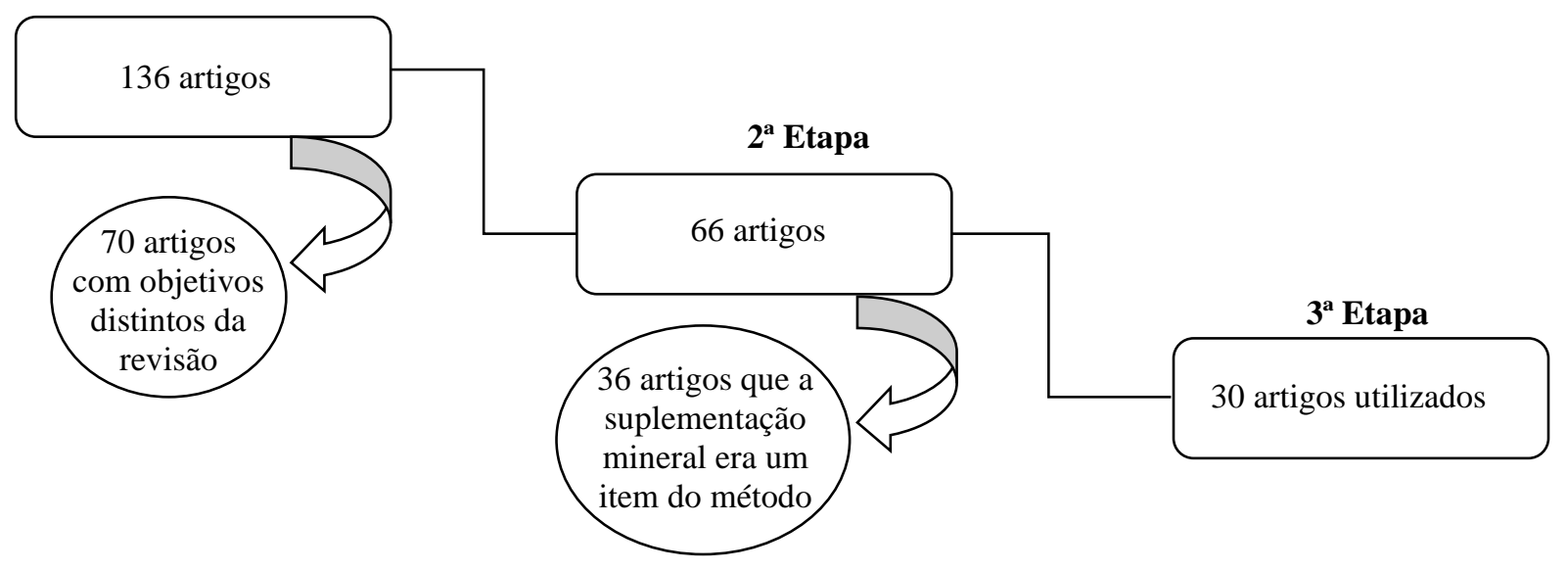

Fonte: Autores.

Tabela 1. Descrição dos autores e ano de publicação, objetivos dos estudos e periódicos em que foram publicados os artigos utilizados na revisão sistemática.

\begin{tabular}{|c|c|c|c|}
\hline Autor & Ano & Objetivos & Periódico \\
\hline Barrêto Jr. et al. & 2008 & $\begin{array}{c}\text { Estudar a relação entre as formas de determinação do status de enxofre em } \\
\text { ruminantes. }\end{array}$ & Acta scientiarum \\
\hline Doncel et al. & 2021 & Revisar a literatura sobre hipomagnesemia em bovinos de corte. & $\begin{array}{l}\text { Pesquisa Veterinária } \\
\text { Brasileira }\end{array}$ \\
\hline Evangelista et al. & 2020 & $\begin{array}{c}\text { Avaliar o efeito da suplementação com sal mineral proteinado, em } \\
\text { comparação ao sal mineral, sobre o ganho de peso e a viabilidade econômica } \\
\text { de bovinos de corte na fase de recria, no período seco. }\end{array}$ & Agroecosistemas \\
\hline Filappi et al. & 2005 & $\begin{array}{l}\text { Abordar os fatores que interferem na nutrição mineral e como a } \\
\text { suplementação mineral vem sendo utilizada para bovinos de corte sob } \\
\text { pastejo. }\end{array}$ & Veterinária Notícias \\
\hline Greghi et al. & 2014 & $\begin{array}{c}\text { Avaliar a utilização de dieta aniônica para vacas no periparto sobre } \\
\text { parâmetros sanguíneos e urinários. }\end{array}$ & $\begin{array}{l}\text { Pesquisa Veterinária } \\
\text { Brasileira }\end{array}$ \\
\hline Harvey et al. & 2021 & $\begin{array}{c}\text { Investigar os impactos da suplementação de vacas de corte com fontes de } \\
\text { minerais orgânicas e inorgânicas na gestação. }\end{array}$ & Animals \\
\hline Krabbe et al. & 2021 & $\begin{array}{l}\text { Identificar os fatores determinantes da decisão de compra de núcleo mineral } \\
\text { por parte dos criadores de gado de corte confinado no Centro Oeste. }\end{array}$ & $\begin{array}{l}\text { Research, Society and } \\
\text { Development }\end{array}$ \\
\hline Malafaia et al. & 2004 & $\begin{array}{l}\text { Comparar o desempenho ponderal e os custos com a suplementação mineral } \\
\text { de bovinos de corte que receberam suplemento mineral seletivo ou comercial }\end{array}$ & $\begin{array}{l}\text { Pesquisa Veterinária } \\
\text { Brasileira }\end{array}$ \\
\hline Malafaia et al. & 2014 & $\begin{array}{c}\text { Descrever os principais equívocos e crendices que existem no meio pecuário } \\
\text { brasileiro sobre as deficiências e a suplementação mineral dos bovinos de } \\
\text { corte }\end{array}$ & $\begin{array}{l}\text { Pesquisa Veterinária } \\
\text { Brasileira }\end{array}$ \\
\hline Martins et al. & 2018 & $\begin{array}{c}\text { Relatar a ocorrência de bócio em bovinos no Estado do Mato Grosso, Brasil, } \\
\text { abordando os aspectos epidemiológicos, clínicos e patológicos dessa } \\
\text { enfermidade. }\end{array}$ & $\begin{array}{l}\text { Pesquisa Veterinária } \\
\text { Brasileira }\end{array}$ \\
\hline Martins et al. & 2020 & $\begin{array}{l}\text { Relatar um surto de intoxicação crônica causada por suplementação } \\
\text { excessiva de cobre em bovinos semi-confinados em estado de Mato Grosso, } \\
\text { Brasil. }\end{array}$ & $\begin{array}{l}\text { Pesquisa Veterinária } \\
\text { Brasileira }\end{array}$ \\
\hline Minervino et al. & 2008 & $\begin{array}{l}\text { Estabelecer alguns índices produtivos da pecuária no município de Santarém, } \\
\text { Pará, visando definir os principais problemas que afetam a sua produtividade. }\end{array}$ & Acta Amazonica \\
\hline Montemór et al. & 2008 & $\begin{array}{c}\text { Avaliar o efeito da suplementação com cromo orgânico sobre o peso corporal } \\
\text { e ganho de peso de bovinos da raça Nelore. }\end{array}$ & Semina: Ciências Agrárias \\
\hline
\end{tabular}




\begin{tabular}{|c|c|c|c|}
\hline Mordenti et al. & 2021 & Resumir as possíveis aplicações de melaço para nutrição animal. & Animals \\
\hline Moreira et al. & 2012 & $\begin{array}{l}\text { Avaliar o desempenho produtivo por meio do ganho de peso, rendimento de } \\
\text { carcaça e previsão de rendimento de cortes cárneos de novilhos castrados, } \\
\text { suplementados com mistura mineral com adição de quelato de cromo } \\
\text { submetidos a um } \\
\text { sistema de pastejo no Pantanal Matogrossense. }\end{array}$ & Comunicata Scientiae \\
\hline $\begin{array}{l}\text { Oliveira Dantas et } \\
\quad \text { al. }\end{array}$ & 2010 & $\begin{array}{l}\text { Descrever as funções dos minerais, os problemas causados pelas deficiências } \\
\text { e relatar as principais fontes utilizadas destes minerais para a bovinocultura } \\
\text { de corte. }\end{array}$ & Uniciências \\
\hline Oliveira et al. & 2014 & $\begin{array}{c}\text { Avaliar o efeito de suplementações sobre o desempenho produtivo e } \\
\text { parâmetros econômicos de novilhos de corte, em fase de recria, manejados } \\
\text { em pastagens durante a época da seca. }\end{array}$ & Acta scientiarum \\
\hline Paris et al. & 2013 & $\begin{array}{l}\text { Avaliar o efeito da suplementação com ureia de liberação lenta em } \\
\text { substituição parcial da ureia comum, presente no sal proteinado de novilhas } \\
\text { pastejando em capim Tifton- } 85 \text { no período do inverno. }\end{array}$ & Semina: Ciências Agrárias \\
\hline Peixoto et al. & 2003 & $\begin{array}{c}\text { Verificar alternativas na suplementação mineral que não impliquem em perda } \\
\text { de produtividade. }\end{array}$ & $\begin{array}{l}\text { Pesquisa Veterinária } \\
\text { Brasileira }\end{array}$ \\
\hline Peixoto et al. & 2005 & $\begin{array}{c}\text { Abordar os equívocos e problemas relacionados com a suplementação } \\
\text { mineral tradicionalmente feita e discutir os principais aspectos da } \\
\text { denominada suplementação mineral seletiva. }\end{array}$ & $\begin{array}{l}\text { Pesquisa Veterinária } \\
\text { Brasileira }\end{array}$ \\
\hline Potter et al. & 2009 & $\begin{array}{l}\text { Avaliar o desenvolvimento corporal de novilhas de corte em pastagem de } \\
\text { azevém recebendo diferentes alternativas de suplementação mineral. }\end{array}$ & Ciência Rural \\
\hline Prado et al. & 2002 & $\begin{array}{l}\text { Avaliar o efeito da suplementação proteica sobre o desempenho de bovinos } \\
\text { em crescimento e terminação }\end{array}$ & Acta scientiarum \\
\hline Sales et al. & 2011 & $\begin{array}{l}\text { Determinar as exigências de macrominerais de novilhos zebuínos em } \\
\text { pastagem de Brachiaria decumbens suplementada com concentrado. }\end{array}$ & $\begin{array}{l}\text { Revista Brasileira de } \\
\text { Zootecnia }\end{array}$ \\
\hline Silva et al. & 2016 & $\begin{array}{c}\text { Comparar as características estruturais, morfológicas e bromatológicas da } \\
\text { forragem e o desempenho de bovinos de corte suplementados com mistura } \\
\text { mineral múltipla. }\end{array}$ & Ciência Rural \\
\hline Silva et al. & 2020 & Relatar dois surtos de cobalto deficiência em bovinos de corte. & $\begin{array}{l}\text { Pesquisa Veterinária } \\
\text { Brasileira }\end{array}$ \\
\hline Silveira & 2017 & $\begin{array}{l}\text { Mostrar a importância do suplemento mineral na alimentação de bovinos, } \\
\text { ressaltando suas funções, dentre as quais temos a prevenção de doenças. }\end{array}$ & Pubvet \\
\hline Socreppa et al. & 2015 & $\begin{array}{c}\text { Verificar o desempenho produtivo e a viabilidade econômica da } \\
\text { suplementação proteico-energética para bovinos de corte em pastejo no } \\
\text { período das águas. }\end{array}$ & $\begin{array}{l}\text { Revista Brasileira de Saúde e } \\
\text { Produção Animal }\end{array}$ \\
\hline Sousa et al. & 2020 & $\begin{array}{c}\text { Verificar o efeito da suplementação com cromo no desempenho de bovinos } \\
\text { durante períodos pré e pós-desmame. }\end{array}$ & $\begin{array}{l}\text { Pesquisa Veterinária } \\
\text { Brasileira }\end{array}$ \\
\hline Teixeira et al. & 2011 & Avaliar quatro fontes de fósforo na suplementação de bovinos em pastagem. & $\begin{array}{l}\text { Revista Brasileira de } \\
\text { Zootecnia }\end{array}$ \\
\hline Valle et al. & 2003 & $\begin{array}{l}\text { Detectar possíveis deficiências minerais em vacas de corte, determinando os } \\
\text { níveis de minerais no sangue e na saliva ao longo do ciclo reprodutivo. }\end{array}$ & $\begin{array}{l}\text { Pesquisa Veterinária } \\
\text { Brasileira }\end{array}$ \\
\hline
\end{tabular}

Fonte: Autores.

\section{Fatores que Afetam o Nível da Suplementação}

A criação de bovinos é uma das principais atividades do agronegócio brasileiro, sendo que gera empregos e desempenha papel importante na economia. Um cuidado minuncioso e eficiente com os animais visando sempre seu bem-estar e um ganho de peso satisfatório para que a atividade seja rentável é de extrema importância. A suplementação mineral, está ligada ao bom desenvolvimento animal e visa suprir as necessidades e corrigir as deficiências e desequilíbrios das dietas dos bovinos (Silveira, 2017).

Quando os animais apresentam desequilíbrios minerais, deficiências que não estejam sendo supridas, estes não desempenham seu máximo potencial. Animais com desequilíbrios se tornam suscetíveis a doenças devido a essa restrição. Ainda, enfermidades podem aparecer pelo fato do desequilíbrio mineral afetar a imunidade e a sanidade do animal. Com as carências e necessidades sanadas, a produtividade e desenvolvimento animal juntamente com uma alimentação adequada, irão atingir seu máximo potencial, gerando assim um melhor custo benefício ao criador (Silveira, 2017).

Estando ciente dos problemas que os desequilíbrios minerais podem causar ao rebanho, superar estes desafios é um ponto chave para o sucesso. Para superá-los é necessário avaliar alguns parâmetros nas propriedades. O levantamento dos manejos utilizados na propriedade é uma ferramenta importante para detectar os pontos de estrangulamento. Ao serem 
detectados pontos passíveis de modificação, medidas devem ser tomadas para corrigir e melhorar esses erros tornando a atividade mais lucrativa e com desempenho avançado (Minervino et al., 2008).

No levantamento geral da propriedade, alguns pontos que podem se encaixar são, o manejo dos solos da propriedade, ou seja, como é feita a adubação e se é feito algum tipo de adubação. Outro ponto são as pastagens: variedades, aptidão, e demais parâmetros. Além disso, é preciso saber o tipo de suplementação mineral fornecida e como ela é fornecida aos animais. Esses são pontos que juntamente com demais fatores, tornam possível determinar índices produtivos da propriedade, ou seja, maneiras de detectar os fatores responsáveis pela menor produção (Minervino et al., 2008).

Ao se falar em manejo do solo para as pastagens, alguns pontos das deficiências minerais dos animais podem ser supridas. Por exemplo, ao realizar a correção do pH e adubação, as pastagens irão absorver esses elementos ao qual depois serão ingeridos pelos animais. Os minerais ingeridos em forma de pastagens podem suprir algumas das deficiências nos bovinos. Essas adubações irão disponibilizar em maior ou menor quantidade, alguns elementos na pastagem, além de aumentar a massa verde de forragem. No entanto, esse procedimento pode tornar-se antieconômico em sistemas pecuários menos intensivos (Peixoto et al., 2005).

Na década de 1980 começou o surgimento dos ditos "quelatos", também conhecidos como minerais orgânicos. Esses minerais possuem uma biodisponibilidade maior do que os minerais não orgânicos. Além da maior biodisponibilidade, os quelatos possuem maior poder de absorção pelos animais e ainda são menos tóxicos. Também não possuem relação de antagonismo entre si. A utilização dos quelatos em suplementos minerais torna a mistura mais biodisponível e o mineral é mais aproveitado pelos animais (Peixoto et al., 2005).

Harvey et al. (2021) identificaram que a suplementação de vacas de corte durante a gestação com Cobalto, Cobre, Manganês e Zinco de fontes orgânicas, influenciou positivamente a produtividade das crias, e a antecipação da puberdade das fêmeas descendentes destas vacas, ou seja, produzindo efeitos de longo prazo.

Outro fator que pode afetar a suplementação mineral são os excessos de minerais fornecidos na suplementação. Um exemplo disso é o excesso de cobre na dieta mineral de bovinos. Teores de 20 a $50 \mathrm{mg} / \mathrm{Kg}$ de matéria seca é potencialmente tóxico aos animais, causando necrose hepática e morte. Esse, portanto, é um cuidado que devemos ter na escolha ou formulação dos suplementos que serão fornecidos aos animais pois, se mal formulados, podem causar perdas irreparáveis nos bovinos, principalmente em sistemas confinados (Martins et al., 2020).

Apesar de serem raros, casos de deficiência de iodo em bovinos ainda são encontrados em nosso país, essa deficiência nos bovinos também é conhecida como bócio, a qual resulta no aumento não inflamatório e não neoplásico da glândula tireóide em animais adultos e recém-nascidos. A causa do bócio é a deficiência nutricional de iodo, afeta principalmente fêmeas prenhes causando abortos e nascimento de animais fracos e subdesenvolvidos. Em surtos acompanhados em três propriedades, os proprietários forneciam aos animais sal mineral juntamente com sal branco não iodado (Martins et al., 2018).

\section{Minerais e sua Importância}

Na nutrição dos bovinos, os minerais desempenham funções importantes para o bom desenvolvimento do animal. Funções estas vitais para o organismo trabalhar perfeitamente. O fósforo desempenha inúmeras funções no organismo. Sabendo que as pastagens brasileiras, principalmente no Brasil Central são pobres nesse mineral, a suplementação dos bovinos a pasto com fosfatos se torna indispensável para bons desempenhos na fazenda (Teixeira et al., 2011).

Pelo fato de extensas áreas do território nacional serem muito pobres em fósforo, sendo que se faz necessário o uso da sua suplementação, numa dieta de bovinos onde a pastagem e/ou a alimentação não supre suas necessidades neste elemento, pode ser necessário suplementar com até 6 gramas por dia do elemento na dieta (Peixoto et al., 2005).

Na região de Santarén-Pará, grande parte dos produtores faz uso de suplementação mineral com misturas comerciais 
completas, contendo macro e microelementos, tendo em mente a importância da suplementação. É baixo o número de produtores que ainda fazem uso de práticas errôneas de suplementação utilizando apenas sal comum, ou sal comum acrescido apenas de microelementos (Minervino et al., 2008).

O cobalto é um importante mineral na composição dos suplementos para os bovinos. Silva et al. (2020), descrevem surtos ocorridos em duas fazendas no Centro-Oeste brasileiro nos quais o uso de um mesmo suplemento mineral, com deficiência de cobalto, provocou morbidade em 3248 bovinos de diferentes idades e letalidade em 506 animais. Os animais que sobreviveram apresentaram crescimento comprometido e queda acentuada dos índices reprodutivos. Ou seja, a suplementação mineral inadequada de cobalto é um risco potencial para a ocorrência de surtos que causam perdas produtivas no curto e longo prazo e a identificação precoce dessa deficiência é essencial para a tomada de decisão a fim de mitigar tais perdas (Silva et al., 2020).

O enxofre é um macro elemento de grande importância na suplementação animal. Os problemas relacionados ao excesso e deficiência desse elemento ocorrem em várias partes do território nacional, muitos produtores utilizam enxofre na alimentação com a premissa de agirem como antiparasitário. Em algumas regiões do Brasil, os solos são ácidos e pobres em enxofre, causando deficiência na dieta dos animais, se não suplementados. Alguns criadores de bovinos a pasto, acreditando que as pastagens supram as necessidades de enxofre nos animais, não realizam a suplementação desse mineral. No estado de São Paulo, baixos teores de enxofre nas pastagens indicam diferentes níveis de deficiência desse mineral em bovinos não suplementados (Barrêto Júnior et al., 2008).

Sousa et al. (2020) investigaram a suplementação com cromo orgânico em bezerros e identificaram que o ganho acumulado de peso foi superior nos bezerros suplementados com cromo antes da desmama, além de reduzir os teores de cortisol e de proteína total durante a desmama. Ou seja, a suplementação contínua e prolongada dos bezerros com cromo orgânico reduziu o estresse provocado pelo manejo de desmama.

O cromo orgânico também foi utilizado na suplementação em experimento com bovinos de corte da raça Nelore criados a pasto, onde foi fornecido aos animais sal mineral com adição do cromo orgânico, sendo que o grupo controle recebeu apenas o sal mineral sem a adição do cromo orgânico. Os resultados do experimento mostraram que os bovinos suplementados com cromo orgânico tiveram melhor desempenho em relação ao ganho de peso vivo. Isso nos mostra que a idade ao abate dos animais pode ser diminuida resultando em maior produção e qualidade da carne, além de tornar a atividade mais eficiente do ponto de vista econômico (Montemór \& Marçal, 2009).

Greghi et al. (2014) identificaram diferença significativa da ação do selênio, administrado para vacas no periparto, como redutor dos casos de retenção de placenta.

Outro fator importante ao se falar em suplementação mineral, é o antagonismo entre alguns minerais. Dependendo da quantidade e do tipo do mineral contido na mistura, ele pode inibir a atuação de outro ou de outros elementos. Um exemplo dessa ação de antagonismo é a utilização de sulfato de ferro em uma mistura mineral. O sulfato de ferro irá diminuir a absorção de fósforo e de cobre nos animais (Peixoto et al., 2005).

Sales et al. (2011) avaliaram as exigências dietéticas de bovinos com ganho diário de 1,0 Kg, para bovinos com 400 Kg de peso corpóreo e as exigências foram de 34,59 g de cálcio, 17,36 de fósforo, 7,82 de magnésio, 5,19 de sódio e 41,11 de potássio por dia.

Alguns minerais resultam em desempenhos surpreendentes na suplementação, no caso de quelatos de cromo adicionados na suplementação mineral de bovinos da raça nelore, resultou em um maior ganho de peso e também um aumento no rendimento de carcaça quente (Moreira et al., 2012). 


\section{Pontos Deficitários na Suplementação Mineral de Bovinos de Corte}

No hemisfério Sul, em países como Nova Zelândia, Austrália e Argentina, a hipomagnesemia é uma das principais causas de morte de bovinos de corte criados a pasto. Em surto da doença no Uruguai, a doença ocorreu no final do outono afetando vacas de corte criadas em pastagem de campo nativo, onde 40 de 225 vacas foram afetadas com a doença sendo que 24 dessas morreram. Para solucionar esse problema, é necessário fazer a correta suplementação sazonal com Mg (Doncel et al., 2021).

Em várias regiões do país os erros na suplementação dos bovinos são comuns. Seja por desconhecimento por parte dos produtores ou com intenção de economizar com a suplementação. No caso da Cidade de Santarén, no Pará, 76\% dos produtores não forneciam fósforo suficientemente para suprir as necessidades de seus rebanhos, com intenção de diminuírem custos, e 30,8\% dos produtores não utilizavam o fósforo como suplemento mineral em suas propriedades (Minervino et al., 2008).

As interações que se referem a solo-planta-animal são bem complexas ao nos referirmos a minerais, e devem ser levadas em conta para se atingir melhores desempenhos na produção. A suplementação mineral tem o intuito de suprir as deficiências dos animais em pastejo, se faz análises de solo e de plantas para se ter dados complementares para definir as carências minerais que os animais estão sofrendo. Apesar das análises de plantas e do solo, é imprescindível o estudo de estados minerais com material proveniente dos animais pois com isso, podemos determinar as carências subclínicas e obter dados mais precisos (Filappi et al., 2005).

Em boa parte das fazendas brasileiras, o uso de misturas minerais comerciais é amplamente utilizado. Tais misturas possuem vários minerais, os quais muitas vezes, não seriam necessários na suplementação do rebanho. Nessas misturas os níveis de cloreto de sódio também podem variar, ocasionando um elevado consumo da mistura ou um baixo consumo. Isso resulta em perdas financeiras pelo consumo excessivo onde pode ser desnecessário e até mesmo intoxicar os animais. É comprovado que a suplementação seletiva corretamente implantada e acompanhada, é uma estratégia aliada na redução expressiva dos custos na suplementação mineral dos bovinos (Malafaia et al., 2004). Para estes autores, a economia das misturas minerais seletivas em relação as misturas minerais comerciais podem ser de três até sete vezes na suplementação animal.

É comum os produtores suplementarem seus animais com as misturas minerais comerciais, tendo o pensamento equivocado que a alimentação não consiga suprir as necessidades dos animais, visando com a suplementação mineral aumentar a produtividade. O uso indiscriminado dessas misturas não traz nenhum benefício adicional. Além de aumentarem os custos de produção, corre-se o risco de ocorrer antagonismo em relação aos minerais realmente necessários. Nos bovinos o cálcio, potássio, magnésio, enxofre, ferro, cromo e o níquel são elementos essenciais, mas em condições naturais eles dificilmente estarão deficientes nas dietas (Malafaia et al., 2014).

Mordenti et al. (2021) relatam que o uso de aditivos, especialmente o melaço de cana-de-açúcar, pode alterar o equilíbrio mineral da dieta, principalmente na relação cálcio : fósforo e isso deve ser levado em consideração na formulação das dietas, a fim de manter seu equilíbrio mineral.

Em experimento conduzido no Noroeste do Paraná, Paris et al. (2013) avaliaram a importância da suplementação de novilhas cruzadas ( $1 \frac{1}{2}$ Red Angus $1 / 2$ Nelore) com peso médio inicial de $240 \mathrm{~kg}$ sob pastejo de Tifton-85 no final do outono e início do inverno. Os autores identificaram consumo médio de 106 gramas por animal por dia de sal mineralizado, não havendo diferença significativa no desempenho dos animais que receberam outras fontes de suplementação, por exemplo proteica, além do sal mineralizado.

Silva et al. (2016) ao avaliarem o desempenho de bovinos de corte no Centro-Oeste do Brasil, verificaram que a oferta de 70 gramas ao dia de mistura mineral e 50 gramas de cloreto de sódio foram suficientes para suprir a demanda mineral dos 
bezerros com aproximadamente oito meses de idade e $200 \mathrm{~kg}$ de peso vivo em sistema de recria sob pastejo contínuo no período seco.

No estado do Rio Grande do Sul existem diversas espécies de gramíneas que servem de alimento em forma de pastejo. E ainda, as mesmas podem ser ensiladas como uma alternativa para os períodos de déficit forrageiro. Boa parte dos produtores, ao terem seus animais em pastejo fornecem suplemento mineral no cocho, com intuito de aumentar o ganho de peso e consecutivamente aumentar seu retorno financeiro. De acordo com Potter et al. (2009), ao avaliarem novilhos de nove a doze meses de idade, sendo alimentados em pastagem de azevém, sem restrições de oferta e consumo, observaram que a pastagem da azevém atendeu todas as exigências nutricionais para ganho de $1 \mathrm{~kg}$ de peso vivo ao dia, independentemente da mineralização utilizada.

Com o intuito de aumentar o ganho de peso de seus animais, alguns produtores fornecem suplementos minerais proteicos. Porém, nem sempre são vantajosos e resultam no potencial esperado. Ao ser utilizada a suplementação mineral proteica, percebe-se aumento nos custos de produção e se torna necessário que os animais retornem o investido para a atividade se tornar cada vez mais rentável. No Norte do Paraná, animais em pastejo de Cynodon plectostachyrus Pilger, que receberam suplementação proteica não resultaram em melhor rendimento de ganho de peso ao serem comparados a animais que receberam apenas suplementação mineral (Prado et al., 2002)

Em experimento feito no Baixo Amazonas Paraense, comparando a suplementação com sal mineral proteico em comparação com suplementação com sal mineral, Evangelista et al. (2020) chegaram à conclusão que a suplementação com sal mineral proteico $(0,1 \%$ do peso vivo), não proporcionou melhor desempenho animal quando comparado ao sal mineral. Ao avaliarem a viabilidade econômica do experimento, foi constatado que a viabilidade dos animais suplementados com sal mineral proteico é a mesma dos que foram suplementados com sal mineral.

\section{Considerações Finais}

Este estudo atingiu os objetivos propostos de aprofundar os conhecimentos sobre a suplementação mineral de bovinos de corte, em diferentes sistemas de produção, através da investigação de trabalhos já publicados sobre o tema.

O estudo foi importante pois permitiu uma melhor organização do banco de dados, além da possibilidade de combinar e sintetizar informações oriundas de múltiplas fontes.

Foi possível evidenciar que a suplementação mineral envolve várias etapas do planejamento para a produção dos bovinos de corte, devendo o produtor possuir uma visão ampla do sistema. Essa visão abrange desde a análise do solo, a implantação e manejo de pastagens, as exigências de diferentes categorias animais e em diferentes épocas do ano, até os ajustes na formulação dos suplementos que serão fornecidos aos animais pois, se mal formulados, podem causar perdas irreparáveis nos bovinos.

Sendo assim, conclui-se que o uso correto de suplementos minerais, trará receitas através da produtividade superior e compensatória aos investimentos com a compra dos suplementos.

Sugere-se que em trabalhos futuros sejam explorados outros aspectos da suplementação mineral de bovinos de corte, discriminando diferentes categorias animais, épocas do ano e regiões do país.

\section{Referências}

Barrêto Jr., R. A., Minervino, A. H. H., Mori, C. S., Sucupira, M. C. A. \& Ortolani, E. L. (2008). Levantamento da concentração de enxofre em capins e de sulfato inorgânico sérico em bovinos criados em fazendas no estado de São Paulo. Acta scientiarum - Animal Sciences. 30(3), 327-332.

Cordeiro, A. M., Oliveira, G. M., Renteía, J. M. \& Guimarães, C. A. (2007). Revisão sistemática: uma revisão narrativa. Revista do Colégio Brasileiro de Cirurgiões. 34(6), 428-431. 
Doncel, B., Puentes, J. D., Caffarena, R. D., Correa, F. R., Costa, R. A. \& Giannitti, F. (2021). Hipomagnesemia em bovinos de corte. Pesquisa Veterinária Brasileira. 41, e06826.

Evangelista, M. S., Azevedo, M. M. R., Sarturi, C., Araújo, J. A. S., Neves, K. A. L., Minervino, A. H. H., Sousa, J. T. R. \& Costa, J. S. (2020). Suplementação com sal mineral proteinado para bovinos de corte, na fase de recria, no período seco, na região do baixo amazonas paraense. Agroecossistemas. $12(2), 175-193$.

Filappi, A., Prestes, D. \& Cecim, M. (2005). Suplementação mineral para bovinos de corte sob pastejo - Revisão. Veterinária Notícias. 11(2), 91-98.

Greghi, G. F., Netto, A. S., Schalch, U. M., Bonato, C. S., Santana, R. S. S., Cunha, J. A., Silva, S. L. \& Zanetti, M. A. (2014). Suplemento mineral aniônico para vacas no periparto:parâmetros sanguíneos, urinários e incidência de patologias de importância na bovinocultura leiteira. Pesquisa Veterinária Brasileira. 34(4), 337-342.

Harvey, K. M., Cooke, R. F. \& Marques, R. S. (2021). Supplementing Trace Minerals to Beef Cows during Gestation to Enhance Productive and Health Responses of the Offspring. Animals. 11, art.1159.

Krabbe, A. A., Palma, A. F., Damasio, V. R., Maciel, W. R. E., Casagranda, Y. G. \& Sanches, A. C. (2021). Atributos da compra que podem influenciar no uso de núcleos minerais para composição da diéta de bovinos de corte em confinamento. Research, Society and Development. 10 (3), e33010312310.

Malafaia, P., Costa, R. M., Brito, M. F., Peixoto, P. V., Barbosa, J. D., Tokarnia, C. H. \& Dobereiner, J. (2014). Equívocos arraigados no meio pecuário sobre deficiências e suplementação minerais em bovinos no Brasil. Pesquisa Veterinária Brasileira. 34(3), $244-249$.

Malafaia, P., Peixoto, P. V., Gonçalves, J. C. S., Moreira, A. L., Costa, D. P. B. \& Correa, W. S. (2004). Ganho de peso e custos em bovinos de corte submetidos a dois tipos de suplementos minerais. Pesquisa Veterinária Brasileira. 24(3), 160-164.

Martins, K. P. F., Fonseca, T. R. S., Silva, E. S., Munhoz, T. C. P., Dias, G. H. S., Galiza, G. J. N., Oliveira, L. G. S. \& Boabaid, F. M. (2018). Bócio em bovinos. Pesquisa Veterinária Brasileira. 38(6), 1030-1037.

Martins, K. P. F., Padilha, V. H. T., Damasceno, T. K., Souza, M. A., Silva, E. M. S., Ribeiro, M., Pereira, A. H. B. \& Colodel, E. M. (2020). Intoxicação crônica por cobre em bovinos de corte no estado de Mato Grosso, Brasil. Pesquisa Veterinária Brasileira. 40(9), 651-661.

Minervino, A. H. H., Cardoso, E. C. \& Ortolani, E. L. (2008). Características do sistema produtivo da pecuária no município de Santarém, Pará. Acta Amazonica. 38(1), 11-16.

Montemór, C. H. \& Marçal, W. S. (2009). Desempenho de bovinos da raça nelore suplementados com cromo orgânico. Semina: Ciências Agrárias. 30(3), 701-708.

Mordenti, A. L., Giaretta, E., Campidonico, L., Parazza, P. \& Formigoni, A. (2021). Review Regarding the Use of Molasses in Animal Nutrition. Animals. 11, art. 115 .

Moreira, P. S. A., Lourenço, F. J., Polizel Neto, A., Heinrich, L. C. \& Berber, R. C. A. (2012). Quelato de cromo em suplementos minerais para bovinos de corte. Comunicata Scientiae. 39(3), 186-191.

Oliveira Dantas, C. C. \& Mattos Negrão, F. (2010). Funções e Sintomas de Deficiência de minerais Essenciais Utilizados para Suplementação dos Bovinos de Corte. Uniciências. 14(2), 199-223.

Oliveira, E. R., Paiva, P. C. A., Babilônia, J. L., Gabriel, A. M. A., Monção, F. P. \& Nascimento, F. A. (2014). Desempenho de novilhos suplementados com misturas minerais na região de mato grosso. Acta Scientiarum-Animal Sciences. 36(3), 329-336.

Paris, W., Marchesan, R., Prohmann, P. E. F., Menezes, L. F. G., Zanotti, J. \& Hartmann, D. V. (2013). Utilização de ureia de liberação lenta em sal mineral nasuplementação de bovinos de corte em pastagem de Tifton-85. Semina: Ciências Agrárias. 34(1), 409-418.

Peixoto, P. V., Malafaia, P., Miranda, L. V., Canella, C. C. F., Canella Filho, C. C. F. \& Vilas Boas, F. V. (2003). Eficiência reprodutiva de matrizes bovinas de corte submetidas a tres diferentes tipos de suplementação mineral. Pesquisa Veterinária Brasileira. 23(3), $125-130$.

Peixoto, P. V., Malafaia, P., Barbosa, J. D. \& Tokarnia, C. H. (2005). Princípios de suplementação mineral em ruminantes. Pesquisa Veterinária Brasileira. 25(3), 195-200

Potter, L., Rocha, M. G., Souza, A. M. N., Roso, D., Glienke, C. L, Costa, V. G., Oliveira Neto, R. A. \& Ilha, G. F. (2009). Desenvolvimento de novilhas de corte sob alternativas de mineralização em pastagem de azevém. Ciência Rural. 39(1), 182-187.

Prado, I. N., Moreira, F. B., Cecato, U., Souza, N. E., Wada, F. Y. \& Nascimento, W. G. (2002). Desempenho de bovinos em crescimento e terminação mantidos em pastagens durante o verão e suplementados com sal proteinado. Acta Scientiarum. 24(4), 1059-1064.

Sales, M. F. L., Paulino, M. F., Valadares Filho, S. C., Porto, M. O., Couto, V. R. M. \& Paulino, P. V. R. (2011). Macromineral requirements by beef cattle under pasture supplementation. Revista Brasileira de Zootecnia. 40(2), 426-432.

Sampaio, R. F. \& Mancini, M. C. (2007). Estudos de revisão sistemática: um guia para síntese criteriosa da evidência científica. Revista Brasileira de Fisioterapia. 11(1), 83-89.

Silva, C. S., Montagnder, D. B., Euclides, V. P. B., Queiroz, C. A. \& Andrade, R. A. S. (2016). Desempenho de novilhos de corte em pastos diferidos de Brachiaria brizantha e Brachiaria decumbens. Ciência Rural. 46(11), 1998-2004.

Silva, W. J., Guizelini, C. C., Franco, G. L., Veiga, R. C. P., Arruda, W. G., Nascimento, V. A., Melo, E. S. P. \& Lemos, R. A. A. (2020). Cobalt deficiency in cattle and its impact on production. Pesquisa Veterinária Brasileira. 40(11), 837-841.

Silveira, L. P. (2017). Suplementação mineral para bovinos. Pubvet. 11(5), 489-500. 
Research, Society and Development, v. 11, n. 3, e39211326616, 2022

(CC BY 4.0) | ISSN 2525-3409 | DOI: http://dx.doi.org/10.33448/rsd-v11i3.26616

Socreppa, L. M., Moraes, E. H. B .K., Moraes, K. A. K., Oliveira, A.S., Drosghic, L. C. A. B., Botini, L. A. \& Stinguel, H. (2015). Glicerina bruta para bovinos de corte em pastejo no período das águas:viabilidade produtiva e econômica. Revista Brasileira de Saúde e Produção Animal. 16(1), $232-243$.

Sousa, I. K. F., Sousa, R. S., Mori, C. S., Morini, A. C., Neves, K. A. L., Minervino, A. H. H. \& Ortolani, E. L. (2020). Influence of organic chromium supplementation on the performance of beef calves undergoing weaning related stress. Pesquisa Veterinária Brasileira. 40(2), 97-101.

Teixeira, S., Branco, A. F., Granzotto, F., Barreto, J. C., Roma, C. F. C. \& Costañeda, R. D. (2011). Fontes de fósforo em suplementos minerais para bovinos de corte em pastagem de Cynodon nlemfuensis Vanderyst. Revista Brasileita de Zootecnia. 40(1), 190-199.

Valle, S. F., González, F. D., Rocha, D., Scalzilli, H. B., Campo, R. \& Larosa, V. L. (2003). Deficiências minerais em gado de corte no sul do Brasil. Revista Brasileira de Pesquisa Veterinária e Zootecnia. 40(supl.), 47-53. 